\title{
Active Aging Health Determinants among Working and Retired Filipino Older Persons Living in an Urban Academic Campus
}

\author{
Shelley Ann F. de la Vega, MD, MSc, ${ }^{1,2}$ Nimfa B. Ogena, PhD, ${ }^{3}$ Maria Stella T. Giron, MD, PhD, ${ }^{1,2}$ \\ Angely P. Garcia, RN, MPH, ${ }^{2}$ Hannah M. Pellejo, PTRP, ${ }^{2}$ \\ Sarah Jane S. Fabito ${ }^{2}$ and Vicente O. Medina III, DMD, $\mathrm{PhD}^{4}$ \\ ${ }^{1}$ College of Medicine, University of the Philippines Manila \\ ${ }^{2}$ Institute on Aging, National Institutes of Health, University of the Philippines Manila \\ ${ }^{3} U P$ Population Institute, College of Social Sciences and Philosophy, University of the Philippines Diliman \\ ${ }^{4}$ College of Dentistry, University of the Philippines Manila
}

\begin{abstract}
Objectives. This study aims to describe the demographic profile and determine the proportion and Active Aging health determinants of staff, faculty, and retired employees who are 55 years of age and older.

Methods. Mixed qualitative and quantitative methods, community-based, and participatory. Participants were working and retired faculty and staff, age 55 years and over, living within an urban campus of a University. The University Ethics Review Board approved the protocol. Focus group discussions (FGDs) led to the development of a pretested survey instrument. Additional health data were obtained using a validated Comprehensive Geriatric Assessment (CGA) tool. Trained and certified health professionals conducted the CGA. A Senior Geriatrician adjudicated the final diagnoses. Progress reports and validation workshops were conducted with study participants, content experts, and stakeholders. CSPRo, SPSS, and STATA were used to generate and analyze disaggregated data.
\end{abstract}

Results. Two hundred thirty-one $(n=231)$ agreed to participate. The matched dataset was used in data analysis, representing a total of $n=192$ completed both surveys and CGA interview. Of the top 10 Geriatrician diagnoses, the highest-ranking non-communicable disease was hypertension and the top sensory diagnosis was presbyopia. Three of the self-assessed conditions were vision-related. They had better oral health than the recent national report. Most were highly independent and functional. The majority rated their QOL as good. Most had access to health insurance and a University Health Service.

An excerpt from this paper was presented as an oral presentation at the International Association of Geriatric and Gerontology Asia-Oceania Convention in October 2019, Taipei, Taiwan.

As part of the participatory approach, results were shared in several meetings with the Steering and Advisory Committees, a Panel of Experts from various medical, government and civil societies, community participants and leadership. The preliminary results of Projects 1 and 2 were also presented in the UP Manila-National Institutes of Health (NIH) Research Forum on December 12, 2017, to initially validate the findings. Attendees were health professionals, faculty, researchers, and stakeholders. Comments and recommendations were noted and were incorporated in the final technical report.

Corresponding author: Shelley Ann F. de la Vega, MD, MSc Institute on Aging

Rm 211 National Institutes of Health

University of the Philippines Manila

Pedro Gil Street, Ermita, Manila 1000, Philippines

Email: sfdelavega@up.edu.ph
Conclusion. Non-communicable diseases and visual disorders were the most common medical problems among working and retired university workers 55 years and older, living within the campus. To reduce NCDs, maintain functional independence and achieve a better quality of life especially among the retired, programs for older persons are recommended. These include access to medication, improved health financing, and senior wellness programs during and after employment. The results of the study will help understand and create a Framework for Active Aging that is relevant to this academic community.

Key Words: Active Aging, Filipinos, Retired, QOL, Geriatric Assessments, University 


\section{INTRODUCTION}

Active aging is the process of optimizing opportunities for health, participation, and security to enhance the quality of life as people age. The WHO Active Aging Policy Framework lists the following determinants that are essential to the achievement of active aging: 1. Health and Social Service; 2. Behavioral; 3. Personal Factors; 4. Physical Environment; 5. Social Environment; and 6. Economic. ${ }^{1}$ The concept of Quality of Life (QOL) is closely linked to active Aging, with its domains overlapping with the essential components of the active aging determinants. ${ }^{2}$

Many academic institutions, here and abroad, are faced with the challenge of an aging faculty and workforce. ${ }^{3}$ Universities are faced with a question of whether to retain their active, robust and senior faculty who are soon to retire or to rehire those who have retired. Our senior citizens play a vital role in national development. This is especially true for the staff, faculty, and retirees in our Universities.

Philippine demographic health data, health, and nutrition surveys and national census data on older persons are available. ${ }^{4,5}$ However, the review of the literature shows that there is no local data to describe the Active Aging indices and correlate these with attributes of objective measures of health and wellbeing. Most data reported are based on selfreported health problems, not diagnosed by a physician. There are also data gaps in the retirement and employment domains. With these, the UP Wellness Initiative for Seniors and Elders (UPWISE) was conceptualized. Using a community-based participatory approach, proponents hope that the UPWISE program will help develop a framework on health and wellness for seniors that will be useful to the academic leadership, policymakers, community, and development partners.

\section{Specific objectives}

1. Determine the proportion and Active Aging health determinants among working staff, faculty and retired employees aged 55 years and older, living in an urban campus.

a. To describe the health status of participants using a Comprehensive Geriatric Assessment (CGA).

b. To describe the Quality of Life (QOL) of participants.

4. Propose recommendations for use in future policies and services that would benefit the health and wellness of senior citizens in the University community.

\section{MATERIALS AND METHODS}

The UPWISE is a four-project, two- campus research program funded by the Emerging Interdisciplinary Research (EIDR), Office of the Vice President for Academic Affairs, University of the Philippines System. This publication will discuss the results of the urban campus. The University Ethics Review Board approved the protocol.

\section{Project Site}

The pilot site for the UPWISE program is Barangay University of the Philippines (UP) campus in Diliman, where many UP employees reside. Its 493 hectares has sixteen (16) political jurisdictions known as "Pook". In 2010, there were 8,356 households in Barangay UP Campus with a total population of 36,486 and approximately 1,000 senior citizens aged 60 and older. There are 385 lessee retirees who occupy UP-owned housing units in UP Diliman.

\section{Sampling and Recruitment}

Participants were 55 years and older, current or retired employees and faculty personnel, living within a defined geographical area around the vicinity of a university campus in the National Capital Region (NCR). A stratified systematic sampling procedure was employed, with subjects stratified according to employment status. A list of eligible respondents was requested from the Human Resources Development Office (HRDO) and supplemented by a separate field list and referrals from co-faculty, barangay office, senior citizens and church groups. The final combined list served as the sampling frame. Assuming about $30 \%$ of the target population is residing in the UPD campus, the preliminary estimate of the population of older persons in UPD was about 1303. Given this, the minimum sample size is 306 with $80 \%$ statistical power. Adjusting for about 16\% non-response, the sample size for the survey (Project 1) and the CGA (Project 2) was increased to 356 . However, due to the large proportion of difficulty in recruitment (i.e., 39\% refusal rate in Project 2) and given the frailty of respondents, perceived fear of knowing more health problems, etc., a second set of samples were drawn from among those not selected in the initial list of sample respondents. All participants were assigned a code to ensure data confidentiality.

Aside from the letter of invitation sent to the participants, the trained research assistants also visited their offices (for working participants) and residences (retired participants) to explain the nature and purpose of the study with the approved informed consent form as a guide. Once agreed to participate, participants were asked about their availability and to schedule their appointment for the health assessment and clinic visits. Criteria for exclusion were the inability to communicate and respond to questions personally, and lack of commitment to follow up on subsequent clinic visits. Homebound patients were included and visited for data collection.

\section{Data Collection}

\section{Project 1: Development of a Survey Instrument}

A Steering Committee was formed, consisting of the project proponent and project leaders, and representatives from the Barangay, Non-government organizations (NGOs), retired employees residing at the campus, and the Office of the Vice President for Academic Affairs (OVPAA). A Community Advisory Board consisting of stakeholders was 
also formed. The original WHO Active Aging framework was presented to the Community Advisory Board for further inputs. These were incorporated in the UPWISE Project 1 framework and were presented to the Steering Committee along with the planned data collection protocol.

Both qualitative and quantitative methods were used. FGDs were carried out before and after the conduct of a sample survey of currently employed and retired senior citizens in the community. The quantitative part of the study involved the conduct of a household survey for older persons in the community. After preliminary results from the survey were generated, post-survey FGDs were conducted to substantiate and further clarify findings. These FGDs were again transcribed and analyzed to form part of the analysis.

Only the Self Assessed Health component of the survey was utilized in this publication.

\section{Project 2: The Comprehensive Geriatric Assessment}

The CGA is a multidimensional, multidisciplinary diagnostic instrument designed to collect data on the medical, psychosocial and functional capabilities and limitations to uncover medical and functional conditions, and risk factors that have not been previously identified and treated. ${ }^{7}$ The CGA for community-dwelling Filipinos were developed by the Committee on Aging of the UP-NIH in 2005. It was further refined and internally validated by the Philippine College of Geriatric Medicine and the Department of Health. Several pre-tests and pilot tests were performed after translation from English to Filipino.

Functional status was assessed using Katz Index of Independence in Activities of Daily Living (ADL) and Lawton Instrumental Activities of Daily Living (IADL). Katz ADL is a tool that measures an older person's ability to perform activities of daily living functionally. ${ }^{8}$ This includes bathing, eating, dressing, toileting, transferring, and continence. Lawton IADL is used to assess more complex activities needed to function in community settings, such as cooking, handling finances, or housekeeping. ${ }^{9}$ The Filipino FNRI Mini-Nutritional Assessment (MNA), was used to identify the risk of malnutrition. ${ }^{10} \mathrm{~A}$ modification of the Fried's Phenotype for Frailty was used as a tool to assess frailty in older persons. ${ }^{11}$ This simple 5 -question scale is an excellent screening test for clinicians to identify frail persons at risk of developing disability as well as a decline in health functioning and mortality. ${ }^{12}$ Using a 5-point scoring system, we measured ambulation through the Timed Up and Go Test; resistance through Handgrip Strength; fatigue, number of illnesses (greater than 5), and loss of weight were derived from the CGA interview. Frailty scores range from 0 to 5 (i.e., 1 point for each component; 0 $=$ best to $5=$ worst $)$ and represent frail $(3$-and above), prefrail (1-2), and robust (0) health status.

Handgrip strength, an indicator of general muscle strength, was measured using the Jamar analog dynamometer. ${ }^{13}$ The Timed Up and Go Test (TUGT) and Functional Reach Test (FRT) were performed using standardized procedures.

A medication review consisted of listing prescription and over-the-counter medications, including herbal and alternative medications taken two weeks before the interview. Quality of life was assessed using the WHOQOL-BREF, a translated and culturally validated tool for Filipino older persons. ${ }^{2}$

After signing the Informed Consent, participants underwent a health interview conducted by a trained health professional, using the structured CGA protocol and screening tests. The physical and neurological evaluation was performed by research trained and board-certified Geriatricians. Oral health evaluation was standardized and performed by trained and board-certified dental health professionals. The final diagnosis was adjudicated by a senior Geriatrician.

All Project 1 survey participants underwent the CGA.

\section{RESULTS}

A total of 231 participants signed the informed consent, with 194 completed the CGA interview, frailty assessment, and functional tests, geriatrician physical and neurological examinations, 189 completed the MNA, handgrip, and QOL tests, and 169 completed the dental health evaluation. One hundred ninety-seven (197) participants in Diliman completed the survey and a total of 194 participants completed the CGA interview. The matched dataset was used in data analysis, representing a total of $\mathrm{n}=192$ completed both survey and CGA interview (Figure 1).

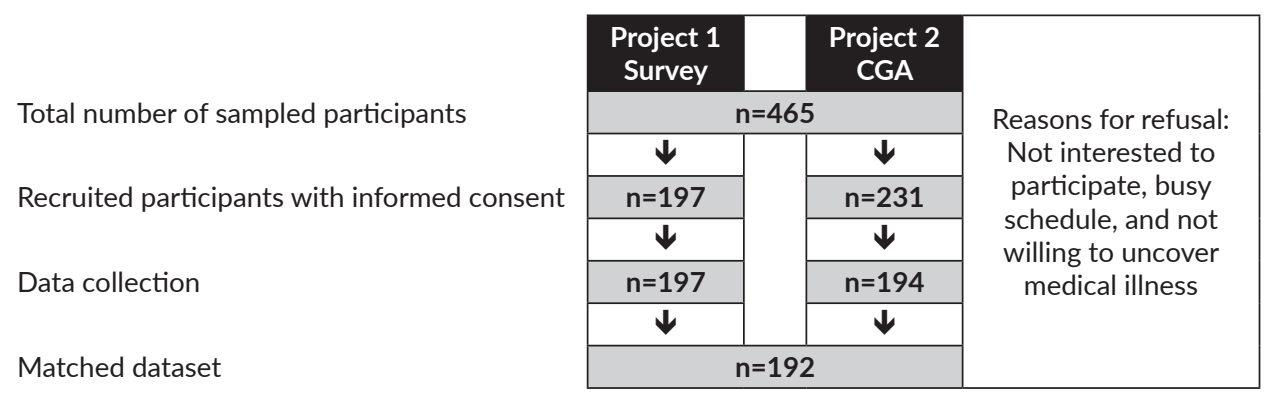

Figure 1. UPWISE Program Recruitment Flow, 2017-2018. 


\section{Demographics}

The mean age was $65.6( \pm 6.6)$ years (range 55-79) with $47.4 \%$ belonging to the $60-69$ age group. There were more males, both in the working and retired groups and the majority were married. Education ranged from 0-19 years (mean $12.3( \pm 3.7)$ ), and almost a quarter had postgraduate education, of which $16.7 \%$ held a master degree and $8.3 \%$ had a doctorate. The most common type of work was service, followed by administrative, academic, and health-related. Forty percent of the participants worked in service, mostly as maintenance personnel, and an almost equal number worked in administration (Table 1).

Almost three fourths $74.5 \%$ were married. Only $12 \%$ were widowed, most of which were retired females. The majority (96.3\%) of the participants were living with others, particularly with family members such as spouses, children, grandchildren, and relatives. Only $3.7 \%$ of the UPWISE participants lived alone. Almost all of the working and retired participants lived with their families and relatives. All of the working participants, in contrast to only $94.6 \%$ of the retired participants, had health insurance.
Only $12.5 \%$ of the total participants had a primary caregiver, of whom most were retired males. In contrast, more participants $(24 \%)$ were providing care for a family member.

\section{Active Aging Health Determinants}

\section{Self-assessed Health}

Project 1 survey participants were asked to rate their health based on their self -perception. Almost half of the participants believed that they were of average health. Around two thirds (67.7\%) believed that they were healthier than people of the same age, but relatively the same health with the previous year (63.5\%). More retired participants $(36.5 \%)$ believed that they were unhealthy and very unhealthy compared to the working group (20.8\%). However, more working participants believed that their health is worse than the previous year (14.6\%) (Table 2).

\section{Lifestyle}

The majority of the CGA participants reported "ever use" of alcohol (77.1\%) and tobacco (52.6\%), with a higher

Table 1. Socio-demographic profile of UP Diliman Participants, 2017-2018

\begin{tabular}{|c|c|c|c|c|c|c|}
\hline \multirow{2}{*}{ Characteristics } & \multicolumn{2}{|c|}{ Total } & \multirow{2}{*}{$\begin{array}{c}\text { Working } \\
\%\end{array}$} & \multirow{2}{*}{$\begin{array}{c}\text { Retired } \\
\%\end{array}$} & \multirow{2}{*}{$\begin{array}{c}\text { Male } \\
\%\end{array}$} & \multirow{2}{*}{$\begin{array}{c}\text { Female } \\
\%\end{array}$} \\
\hline & $f$ & $\%$ & & & & \\
\hline$N$ of cases & 192 & 100.0 & 96 & 96 & 109 & 83 \\
\hline Age (mean $\pm S D)$ & $65.5( \pm 6.6)$ & 100.0 & $60.2( \pm 2.9)$ & $71.1( \pm 4.3)$ & $66.3( \pm 6.1)$ & $64.4( \pm 7.0)$ \\
\hline $55-59$ & 45 & 23.4 & 45.8 & 1.0 & 17.4 & 31.3 \\
\hline $60-69$ & 91 & 47.4 & 54.2 & 40.6 & 49.5 & 44.6 \\
\hline $70-79$ & 56 & 29.2 & 0.0 & 58.3 & 33.0 & 24.1 \\
\hline 80 and above & 0.0 & 0.0 & 0.0 & 0.0 & 0.0 & 0.0 \\
\hline \multicolumn{7}{|l|}{ Civil status } \\
\hline Married/Live in & 143 & 74.5 & 74.0 & 75.0 & 84.4 & 61.5 \\
\hline Widowed & 23 & 12.0 & 7.3 & 16.7 & 8.3 & 16.9 \\
\hline Single (Never married) & 16 & 8.3 & 12.5 & 4.2 & 1.8 & 16.9 \\
\hline Divorced /separated & 10 & 5.2 & 6.3 & 4.2 & 5.5 & 4.8 \\
\hline Education (mean no. of yrs $\pm S D$ ) & \multicolumn{2}{|c|}{$12.3( \pm 3.7)$} & $13.6( \pm 3.0)$ & $11.1( \pm 3.9)$ & $11.2( \pm 3.9)$ & $13.8( \pm 2.8)$ \\
\hline High school or less & 60 & 31.3 & 17.7 & 44.8 & 45.0 & 13.3 \\
\hline With post-secondary/ vocational & 19 & 9.9 & 10.4 & 9.4 & 13.8 & 4.8 \\
\hline With college & 65 & 33.9 & 36.5 & 31.3 & 26.6 & 43.4 \\
\hline With MS & 32 & 16.7 & 24.0 & 9.4 & 5.5 & 31.3 \\
\hline With PhD/Post-doctoral & 16 & 8.3 & 11.5 & 5.2 & 9.2 & 7.2 \\
\hline \multicolumn{7}{|l|}{ Type of work } \\
\hline Service & 78 & 40.6 & 20.8 & 60.4 & 62.4 & 12.1 \\
\hline Administrative & 76 & 39.6 & 54.2 & 25.0 & 23.9 & 60.2 \\
\hline Academe & 36 & 18.8 & 22.9 & 14.6 & 13.8 & 25.3 \\
\hline Health-related & 2 & 1.0 & 2.1 & 0.0 & 0.0 & 2.4 \\
\hline \multicolumn{7}{|l|}{ Living arrangement } \\
\hline Living alone & 7 & 3.7 & 3.1 & 4.2 & 4.6 & 2.4 \\
\hline Living with others & 185 & 96.3 & 96.9 & 95.8 & 95.4 & 97.6 \\
\hline Nuclear family & 172 & 89.6 & 86.5 & 92.7 & 91.7 & 86.8 \\
\hline Grandchildren & 89 & 46.4 & 29.2 & 63.5 & 53.2 & 37.4 \\
\hline Other relatives & 40 & 20.8 & 21.9 & 19.8 & 16.5 & 26.5 \\
\hline Health insurance & 187 & 97.4 & 100.0 & 94.6 & 95.4 & 100.0 \\
\hline Primary caregiver & 24 & 12.5 & 3.0 & 22.6 & 17.4 & 6.0 \\
\hline Caring for family & 46 & 24.0 & 24.2 & 23.7 & 24.8 & 22.9 \\
\hline
\end{tabular}


Table 2. Self-Assessed Health of UPWISE Diliman Participants, 2017-2018

\begin{tabular}{|c|c|c|c|c|c|c|}
\hline \multirow{2}{*}{ Self-assessed health } & \multicolumn{2}{|c|}{ Total } & \multirow{2}{*}{$\frac{\text { Working }}{\%}$} & \multirow{2}{*}{$\begin{array}{c}\text { Retired } \\
\%\end{array}$} & \multirow{2}{*}{$\begin{array}{c}\text { Male } \\
\%\end{array}$} & \multirow{2}{*}{$\begin{array}{c}\text { Female } \\
\%\end{array}$} \\
\hline & f & $\%$ & & & & \\
\hline$N$ of cases & 192 & 100.0 & 96 & 96 & 109 & 83 \\
\hline \multicolumn{7}{|l|}{ Self-assessed health } \\
\hline Very healthy & 18 & 9.4 & 13.5 & 5.2 & 9.2 & 9.6 \\
\hline Healthier than average & 31 & 16.1 & 15.6 & 16.7 & 14.7 & 18.1 \\
\hline Of average health & 88 & 45.8 & 50.0 & 41.7 & 44.0 & 48.2 \\
\hline Somewhat unhealthy & 51 & 26.6 & 20.8 & 32.3 & 29.4 & 22.9 \\
\hline Very unhealthy & 4 & 2.1 & 0.0 & 4.2 & 2.8 & 1.2 \\
\hline \multicolumn{7}{|c|}{ Self-assessed health relative to others of the same age } \\
\hline Better & 130 & 67.7 & 66.7 & 68.8 & 67.0 & 68.7 \\
\hline Relatively the same & 56 & 29.2 & 31.3 & 27.1 & 29.4 & 28.9 \\
\hline Worse & 6 & 3.1 & 2.1 & 4.2 & 3.7 & 2.4 \\
\hline \multicolumn{7}{|c|}{ Self-assessed health relative to the previous year } \\
\hline Better & 47 & 24.5 & 22.9 & 26.0 & 24.8 & 24.1 \\
\hline Relatively the same & 122 & 63.5 & 62.5 & 64.6 & 64.2 & 62.7 \\
\hline Worse & 23 & 12.0 & 14.6 & 9.4 & 11.0. & 13.3 \\
\hline
\end{tabular}

Table 3. Behavior, Lifestyle, and Physical Activity of UPWISE Diliman Participants, 2017-2018

\begin{tabular}{|c|c|c|c|c|c|c|}
\hline \multirow{2}{*}{ Behavior and lifestyle } & \multicolumn{2}{|c|}{ Total } & \multirow{2}{*}{$\begin{array}{c}\text { Working } \\
\%\end{array}$} & \multirow{2}{*}{$\begin{array}{c}\text { Retired } \\
\%\end{array}$} & \multirow{2}{*}{$\begin{array}{c}\text { Male } \\
\%\end{array}$} & \multirow{2}{*}{$\begin{array}{c}\text { Female } \\
\%\end{array}$} \\
\hline & $f$ & $\%$ & & & & \\
\hline$N$ of cases & 192 & 100.0 & 96 & 96 & 109 & 83 \\
\hline \multicolumn{7}{|l|}{ Alcohol } \\
\hline Ever use & 148 & 77.1 & 77.1 & 77.1 & 96.3 & 51.8 \\
\hline Current use & 95 & 64.2 & 75.7 & 52.7 & 64.8 & 62.8 \\
\hline \multicolumn{7}{|l|}{ Tobacco } \\
\hline Ever smoker & 101 & 52.6 & 49.0 & 56.3 & 77.1 & 20.5 \\
\hline Current smoker & 21 & 21.0 & 28.3 & 14.8 & 22.9 & 11.8 \\
\hline \multicolumn{7}{|l|}{ Physical activity } \\
\hline With exercise & 170 & 88.5 & 95.8 & 88.5 & 90.8 & 85.5 \\
\hline Without exercise & 22 & 11.5 & 4.2 & 11.5 & 9.2 & 14.5 \\
\hline
\end{tabular}

proportion among males. Among those who ever used alcohol, a big majority (64.2\%) were currently drinking, with a higher proportion among the working and almost equal proportion among males and females. In terms of tobacco use, there were more working and male participants who reported current smoking. Furthermore, there was more than a $50 \%$ decrease from those who ever smoked to current smoking (Table 3).

\section{Physical Activity}

The participants were asked if they perform some form of exercise. Most (88.5\%) of the participants reported that they exercise, with a slightly higher proportion among the working and males (Table 3 ).

\section{Level of Independence}

Higher ADL scores mean that the participant is independent. Most of the participants were independent, especially those working. Very few retired participants needed some form of assistance in terms of bathing, toileting, and in controlling the urge to urinate or defecate.

\section{Self-reported Disease}

Hypertension was the leading self-reported disease, followed by sensory and endocrine/metabolic problems. Presbycusis, urinary tract infection and osteoarthritis were also included in the Top 10 self-reported diseases. Visual impairments were more commonly reported by the retired population (Figure 2).

\section{Top NCDs based on the CGA}

Hypertension, hyperuricemia, dyslipidemia, Type 2 diabetes mellitus, and macular degeneration were the top 5 NCDs reported by the respondents. More retired had these conditions, while more working participants had diabetes, age-related macular degeneration, and acid peptic disease. The CGA yielded organ system problems with the sensory organ system as the most reported, followed by cardiovascular, endocrine, musculoskeletal and genitourinary. More retired persons reported sensory and respiratory problems. The most common sensory problem reported were errors of refraction (i.e. near-sightedness, farsightedness, and astigmatism). There were more working participants 
with EOR and vertigo, while more retired had cataracts and experienced hearing loss (Figure 3).

\section{Geriatrician Diagnosis}

Of the top adjudicated Geriatrician diagnoses, the highest-ranking NCD was hypertension and the highestranking sensory problem was presbyopia, followed by osteoarthritis, sleep disturbance, dyslipidemia, and type 2 diabetes mellitus. Although osteoarthritis was the third most common geriatrician diagnosis, many did not selfreport this condition. Visual impairments (presbyopia, EOR, and cataracts) were mostly diagnosed among working participants, and hearing impairments were more common among the retired. Erectile dysfunction was also among the top 10 geriatrician diagnoses and again was not included among the top self-reported conditions (Figure 4).

\section{Medications}

Antihypertensives ranked first with $60.4 \%$ of all participants taking this type of medication, followed by Vitamin B complex, multivitamins, antidiabetics, antithrombotics at the top of the list. The top 10 list is consistent with the geriatrician diagnosed problems.

There were more retired who took antihypertensives, Vitamin B complex, multivitamins, antidiabetics, antithrombotics, insulin, and anti-vertigo while more working took NSAIDs, lipid-lowering agents, calcium, anti-asthma, cardiac drugs, and antihistamines. In terms of gender, more females were taking antihypertensives, Vitamin B complex, multivitamins, lipid-lowering agents, calcium, cardiac drugs, antihistamine, and anti-vertigo. On the other hand, more males took anti-diabetics, anti-thrombotic, NSAIDs, anti-asthma, and insulin (Table 4).

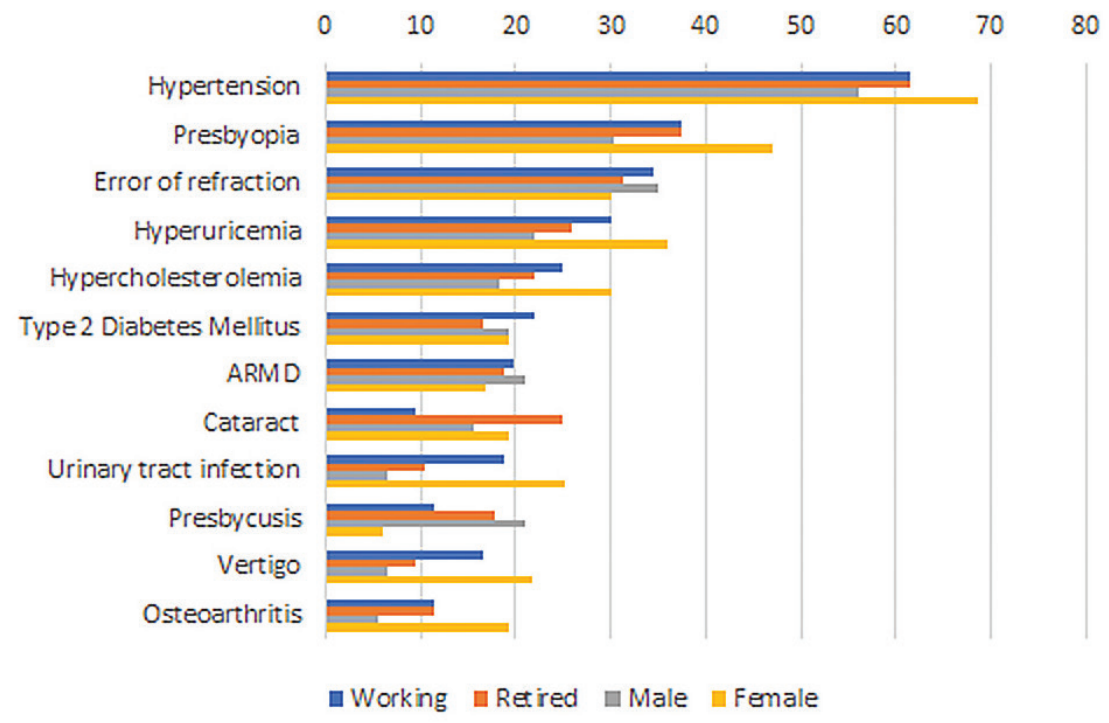

Figure 2. Self-Reported Disease of UPWISE Diliman Participants, 2017-2018.

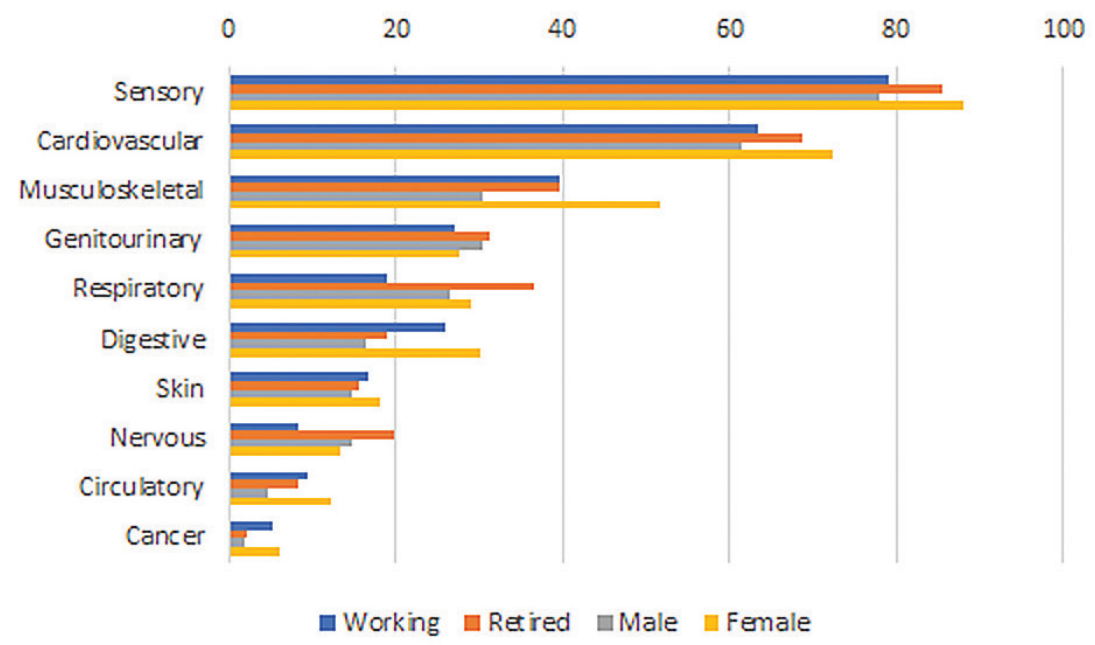

Figure 3. Affected Organ Systems of UPWISE Diliman Participants, 2017-2018. 
Table 4. Top 10 Medications Reported of UPWISE Diliman Participants, 2017-2018

\begin{tabular}{|c|c|c|c|c|c|c|c|}
\hline \multirow{2}{*}{ Rank } & \multirow{2}{*}{ Medicines } & \multicolumn{2}{|c|}{ Total } & \multirow{2}{*}{$\begin{array}{c}\text { Working } \\
\%\end{array}$} & \multirow{2}{*}{$\begin{array}{c}\text { Retired } \\
\%\end{array}$} & \multirow{2}{*}{$\begin{array}{c}\text { Male } \\
\%\end{array}$} & \multirow{2}{*}{$\frac{\text { Female }}{\%}$} \\
\hline & & $f$ & $\%$ & & & & \\
\hline 1 & Anti-hypertensives & 116 & 60.4 & 59.4 & 61.5 & 52.3 & 71.1 \\
\hline 2 & Vitamin B complex & 47 & 24.5 & 21.9 & 27.1 & 16.5 & 34.9 \\
\hline 3 & Multivitamins & 30 & 15.6 & 17.7 & 13.5 & 13.8 & 18.1 \\
\hline 4 & Anti-diabetics & 31 & 16.1 & 17.7 & 14.6 & 17.4 & 14.5 \\
\hline 5 & Anti-thrombotics & 21 & 10.9 & 12.5 & 9.4 & 11.0 & 10.8 \\
\hline 5 & Non-steroidal anti-inflammatory drugs & 21 & 10.9 & 4.2 & 17.7 & 13.8 & 7.2 \\
\hline 6 & Lipid lowering agents & 19 & 9.9 & 9.4 & 10.4 & 9.2 & 10.8 \\
\hline 7 & Calcium & 8 & 4.2 & 3.1 & 5.2 & 2.8 & 6.0 \\
\hline 7 & Anti-asthma & 8 & 4.2 & 1.0 & 7.3 & 5.5 & 2.4 \\
\hline 8 & Cardiac drugs & 7 & 3.6 & 3.1 & 4.2 & 1.8 & 6.0 \\
\hline 9 & Anti-gout & 6 & 3.1 & 3.1 & 3.1 & 2.8 & 3.6 \\
\hline 9 & Antihistamine & 6 & 3.1 & 1.0 & 5.2 & 0.9 & 6.0 \\
\hline 10 & Insulin & 5 & 2.6 & 3.1 & 2.1 & 2.8 & 2.4 \\
\hline 10 & Anti-vertigo & 5 & 2.6 & 3.1 & 2.1 & 0.0 & 6.0 \\
\hline
\end{tabular}

\section{Supplements and Alternative Therapies}

Only two (2) of the $10 \mathrm{DOH}$-approved herbal medicines or halamang gamot were utilized by the participants namely Sambong (2.6\%) and Lagundi (2.1\%). More retired female participants took these.

Only a few took supplements, with mangosteen ranking first, followed by fish oil, lutein, silymarin, dietary fiber, minerals, and others. More females and working participants were taking mangosteen. The participants regardless of working status and sex were taking various types of supplements as noted by $5.2 \%$ of Others.

\section{Oral Health}

Of the 165 participants that completed a dental evaluation, the mean score for Decayed, Missing and Filled Teeth (DMFT) was 19.2. The prevalence of periodontal disease was $37 \%$ and dental caries was $38.0 \%$. The most common oral health treatment need was prosthodontic rehabilitation (95.0\%), followed by scaling and polishing for the management of gingivitis (47.3\%), filling of decayed teeth $(38.0 \%)$, management of periodontal disease (37.0\%), filling of erosion lesions (29.0\%), and extraction of non-restorable teeth (27.0\%).

\section{Vaccination}

There was very poor uptake of vaccines in general. Influenza vaccination was most commonly received (24.0\%) by more than a third of females $(36.1 \%$ vs. $14.7 \%)$ and slightly more than a quarter of the working $(28.1 \%$ vs. $19.8 \%$ ). Pneumococcal vaccination was second most received $(21.9 \%)$, mostly by the retired $(30.2 \%$ vs. $13.5 \%)$, and followed by tetanus (12.5\%), hepatitis (4.2\%), and herpes zoster (1.0\%).

\section{Quality of life}

Using the WHOQOL-BREF, ratings corresponded to the following scores: Good $\geq 88$ and $\leq 123$; Moderate $\geq 56$ and $\leq 87$; Poor $\geq 24$ and $\leq 55$. A great majority $81.5 \%$ rated their QOL as good, and 34\% as moderate. Nobody rated their QOL as poor. Retired persons had slightly lower QOL ratings.

\section{Referral Systems}

Of the total participants, $90.4 \%$ reported that they consulted with a healthcare provider. The majority were seeing a medical doctor (86.0\%) followed by a dentist (51.2\%), nurse (12.6\%) and traditional healer (11.6\%). The allied health professional most consulted was a physical therapist (8.3\%), and only one of the participants had consulted with a geriatrician. Traditional healers were still widely consulted by the participants. Midwives and psychologists were the least consulted by the participants (Figure 5).

More than half of the participants (51.6\%) consulted two or more times with a doctor/physician during the last 12 months with a slightly higher proportion among the retired $(53.1 \%$ vs. $50.0 \%)$. On the other hand, there were more males (28.4\%) who had no consultation with a physician for the past 12 months compared to females (13.3\%).

In terms of health facilities, the majority (63.5\%) of the participants sought care at the University Health Service, with the working population preferring this site more than the retired $(71.0 \%$ vs. $56.3 \%)$. More retirees preferred to consult at a public hospital/health compared to a private facility ( $25.0 \%$ vs. $6.5 \%)$.

\section{Expenditures and Sources of Funds}

The average expenditure per consultation was PHP 879.00 ( \pm 116.00$)$. Females had higher mean expenditure compared to males (PHP 1,000.00 vs. PHP 764.00) and working participants spent slightly more than the retired (PHP 897.00 vs. PHP 860.00). The leading sources were salary (39.1\%), pension (27.6\%) and free consultations (21.4\%). The participants relied more on their children (10.4\%) than their spouses (2.1\%) for financial support. 


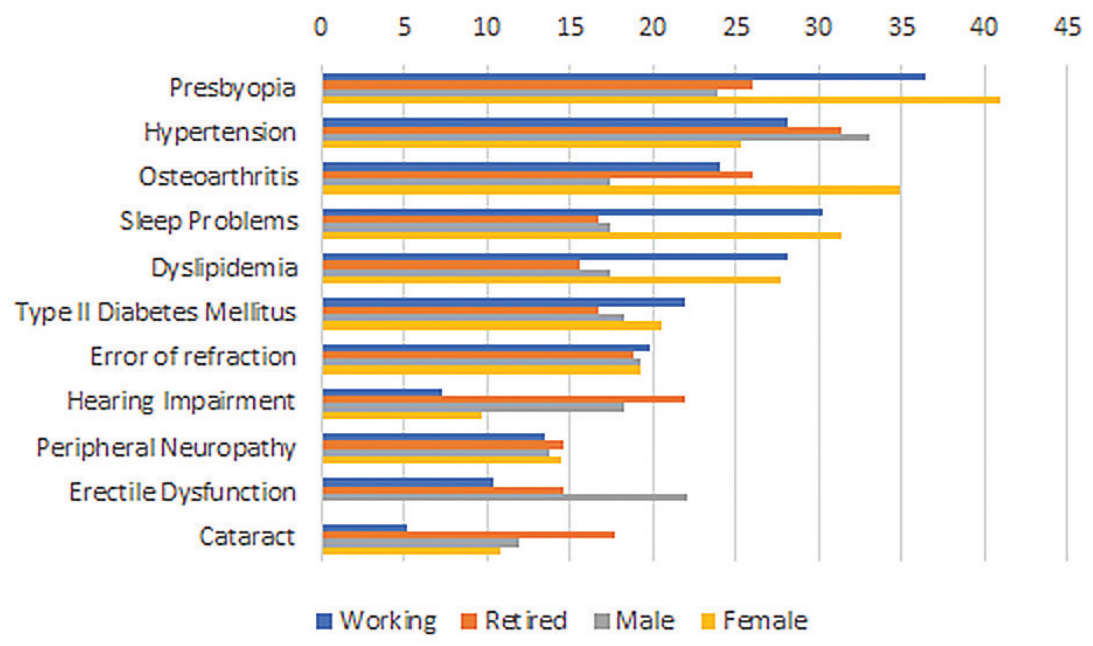

Figure 4. Top Geriatrician Diagnoses among the UPWISE Diliman Participants, 2017-2018.

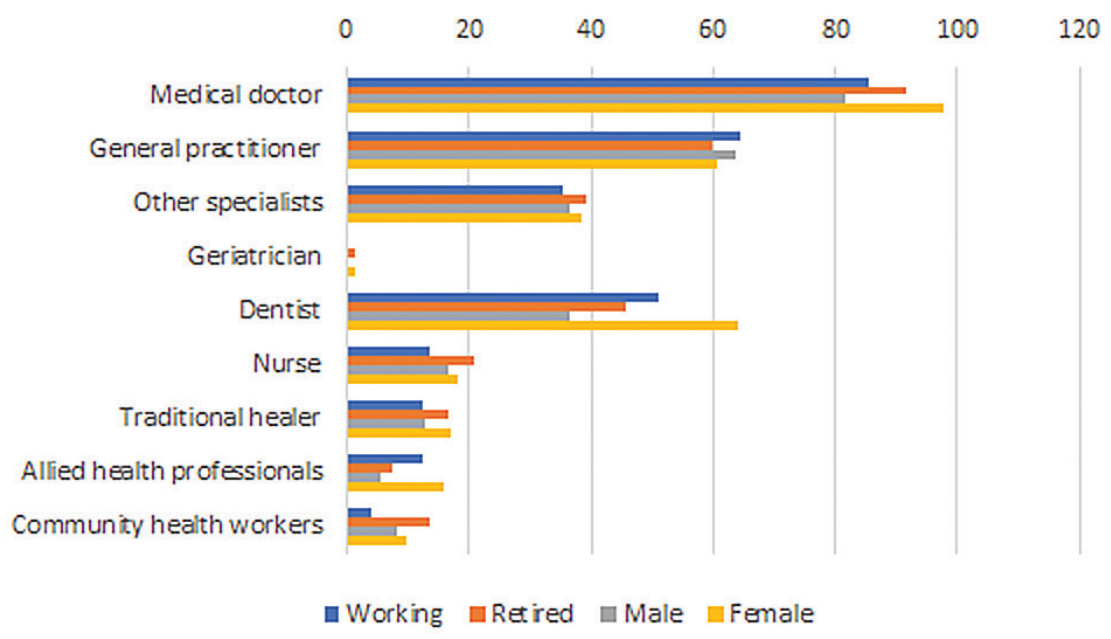

Figure 5. Consultations of UPWISE Diliman Participants by Healthcare Providers, 2017-2018.

All of the University personnel whether retired or working automatically should have been Philhealth members. Nevertheless, there were a few retired employees that did not report membership to Philhealth. Only $13 \%$ of the sample respondents had private $\mathrm{HMO}$ coverage for themselves with a large differential by employment status. About $23 \%$ of the working respondents had their HMO membership compared to only $3 \%$ among the retired respondents.

\section{DISCUSSION AND CONCLUSION}

In this study, the active aging determinants were described among the staff, faculty and retired university employees in the Philippines. In many of the determinants, the sample exhibited better health status than the general population of older Filipinos. The results can be compared with the nationwide Longitudinal Study of Ageing and Health in the Philippines (LSAHP) study where a representative sample of 5,985 older Filipinos across different regions in the country. ${ }^{14}$ In terms of physical activity, $88.5 \%$ of our cohort did physical activity, mostly in the form of brisk walking and stretching. In the LSAHP study, however, only $52.3 \%$ did physical exercises, including walking and dancing. A possible explanation for the better physical activity among university employees was the presence of sufficient green spaces within the campus that may be facilitative for exercise. There were more working participants, 95.8\%, engaged in physical activity compared to retired participants, which was contrary to what other literature suggested. In Germany and the US, retirement increases the probability that older persons engage in leisure-time physical activity and exercise. ${ }^{15}$ In another study, Filipino retired respondents had more free time to enjoy recreational activities than when they were employed. ${ }^{16}$ The difference may be due to the environmental structure of the campus, which requires walking and climbing stairs within and between campus 
buildings. Furthermore, working participants had more family responsibilities, since $46.4 \%$ of the participants lived with their grandchildren and $24.0 \%$ were taking care of family members.

In terms of lifestyle and behavior, compared to the LSAHP data, there was a higher proportion of study participants who are current alcohol drinkers (64.2\% vs. $28.8 \%)$ and current smokers $(21.0 \%$ vs. $17.1 \%)$. The same goes for the previous drinkers $(77.1 \%$ vs. $33.7 \%)$ and previous smokers $(52.6 \%$ vs. $17.1 \%)$. For the retired participants, however, the proportion of current smokers is lower than the LSAHP data (14.8\% vs. $17.1 \%)$. Other studies, however, claim that retirement resulted in increased alcohol consumption. . $^{15,17}$

In terms of self-reported diseases, hypertension was leading (61.5\%), higher than nationwide data (45.5\%). It should be noted, however, that after objective assessment by the geriatrician, presbyopia was the leading disease (31.3\%), followed by hypertension (29.7\%). This indicated the significance of sensory problems among older persons, considering the sensory system was the most affected organ system in the study population, particularly vision. Osteoarthritis was also in the top diseases but was not self-reported by the participants, which may be attributed to the belief that joint pain is a "normal" part of aging. The medications taken by the participants were likewise consistent with their illnesses. Only two DOH-recognized herbal medicines ${ }^{18}$ were taken, namely sambong and lagundi, while the leading supplement was mangosteen. This may highlight the impact of advertising that was mainly used in endorsing mangosteen, but not for $\mathrm{DOH}$-recognized herbal medicines.

Access to health services and facilities was also better for the participants than one from LSAHP. In terms of consultations, $90.4 \%$ of the participants consulted, with the majority having two or more consults in the past 12 months. This is more than twice the numbers in the LSAHP study where only $41.6 \%$ had outpatient consultation and $29.0 \%$ falling ill but not consulting in the past 12 months. The reason may be financial as $21.0 \%$ stated that financial issues were the main reason for such failure to seek consultation. ${ }^{14}$ The significant increase in health-seeking behavior among the university sample can be attributed to the presence of a university health clinic, where the majority of the working and retired participants seek consultation. Working employees enjoy the privilege of having free medical and dental consultations, although this is not extended to retired employees. Many of the participants also have children working in the same university and hence, avail of the free university health services by being dependent on their child.

Access is enhanced not just by the proximity of the university clinic, but also by free and discounted services available to many of the participants. This is also supported by a study on equity in health benefit utilization and financial risk protection in outpatient and inpatient care in a university-based health facility. ${ }^{19}$ The study showed that non-faculty inpatients utilized health insurance more frequently than faculty inpatients $(75.7 \%$ vs. $6.6 \%)$, but paid higher out-of-pocket proportions. In terms of outpatient care, health benefit utilization rates were higher among nonfaculty $(12.4 \%$ vs. $2.1 \%)$. The findings confirmed inequities in accessing health services and utilizing health insurance benefits among faculty and non-faculty.

Access can likewise be the reason why the UPWISE participants consulted more with doctors (86.0\%), dentists (51.2\%), and nurses (12.6\%), while in the LSAHP study, the participants consulted with doctors (91.1\%), midwives $(3.5 \%)$ and nurses (3.4\%). While the majority of the UPWISE participants had doctors and dentists in the clinic, primary access of older persons in the country in the lower socioeconomic bracket is through the barangay health station, which usually employs a community doctor, a midwife, and a nurse.

The high educational attainment of the UPWISE participants may have contributed to better health awareness, considering that more than half had a college or postgraduate degree as compared to LSAHP where a big majority (66.3\%) only finished elementary education. This hypothesis was supported by other studies where older people with higher educational attainment have increased chances of having better health status ${ }^{20}$ or higher scores in the successful aging index. ${ }^{21}$ Likewise, multiple studies have shown that higher educational attainment among older persons resulted in better quality of life ${ }^{17,22}$ and life satisfaction. ${ }^{23}$ Two studies also showed that older university instructors and professors reported better life satisfaction..$^{22,24}$ These conform with the UPWISE findings where most of them rated their quality of life as good (81.5\%) and a great number $(45.8 \%)$ of participants believed they are of average health, similar to LSAHP at $47.6 \%$.

Provided that UP employees have greater access to dental services through the university clinic than the majority of older Filipinos, oral healthcare for this study population was better than the $\mathrm{DOH}$ statistics. The mean score for the decayed, missing, filled teeth is 19.2 compared to 22.9 from the National Monitoring and Evaluation Dental Survey 2011 (NMEDS) of the Department of Health. Periodontal disease and dental caries are likewise lower at $37.0 \%$ and $38 \%$ compared to $45.1 \%$ and $98.8 \%,{ }^{25}$ respectively. Additionally, almost all (95.0\%) had dentures while only $31.7 \%$ from the LSAHP had dentures. Aside from the privilege of having accessible and free services at the university clinic, the huge difference may be attributed to the fact that the national health insurance program (PhilHealth) still does not cover dental services. ${ }^{26}$ Since almost a quarter of older persons in the country live in poverty, ${ }^{22}$ the absence of insurancecovered dental services becomes another barrier to health among older persons.

Although the government mandated that all senior citizens are covered by the national health insurance program 
under R.A. 10645, a small percentage of the participants reported that they did not have health insurance. Thirteen percent claimed to have private health insurance, double than LSAHP findings which are 6.5\%. Despite these measures, UPWISE participants disclosed that their main sources for consults were salary, pension, and free consultations. The older persons claimed that salary and pension were the most important sources of their income. ${ }^{14}$ Lack of awareness may also play a role since, in the Philippines, only $4.6 \%$ of the population were aware of the primary benefit package of PhilHealth. ${ }^{26}$ Hence, under-usage of Philhealth benefits may have resulted in increased out-of-pocket expenditures for the UPWISE participants.

Provided the limited sources of income-particularly for the retired $-10.4 \%$ of the participants relied on their children for their health consultation needs. A higher number (31.3\%) relied on their children for daily needs but was still lower than those from LSAHP findings, which was at $73.1 \%$. It is not, however, uncommon to see older Filipinos rely on their children for financial assistance. The most common issue faced by older persons is inadequate household income (58.7\%). ${ }^{17}$ Economic problems also ranked as the highest problem area in the study of retired faculty. ${ }^{27}$ The findings from the LSAHP revealed that $42.8 \%$ of older Filipinos have difficulty meeting expenses and $46.4 \%$ request money from their children to meet the deficiency. A possible explanation for this is the high dependence ratio on older persons during their working years from younger members of the family, preventing them from saving for retirement. ${ }^{22}$ Provided this, participants from a foreign study on university professors suggested that before retirement, they wanted earlier financial planning, a better life insurance plan, and having the first year of retirement as sabbatical without pay. ${ }^{24}$ Financial standing is likewise directly associated with health, as older persons in the higher socioeconomic bracket have higher scores in the successful aging inde $\mathrm{x}^{21}$ and overall life satisfaction. ${ }^{23,28}$

Access to vaccination was likewise affected by financial standing since pneumococcal and influenza vaccinations are not yet covered by PhilHealth. ${ }^{26}$ The Philippines is yet to provide adequate attention to elderly vaccination, as more focus is still given to infant vaccination. ${ }^{29}$ Hence, it was expected that only a minority of the UPWISE participants had flu and pneumococcal vaccination since these are accessed either through out-of-pocket payments or medical missions. This is similar to the findings wherein poor older adults had lower vaccination coverage compared to more affluent participants. ${ }^{30}$

Specific measures provided by the UP Administration have increased access provided to the health status of working and retired employees. However, difficulties are still evident given the limited insurance benefits offered by the government, which may be one of the crucial mechanisms to curb inequity due to financial limitations. Likewise, access to healthcare is more readily available to working rather than retired employees, hence necessitating programs that may assist university retirees in managing their health.

Non-communicable diseases and visual disorders were the most common medical problems among working and retired university workers 55 years and older, living within the campus. To reduce $\mathrm{NCD}$ s, maintain functional independence and achieve a better quality of life especially among the retired, programs for older persons are recommended. These include access to medication, improved health financing, and senior wellness programs during and after employment. The results of the study will help understand and create a Framework for Active Aging that is relevant to this academic community.

This study has several limitations. One is the low response rate of the participants. Characteristics of chosen samples who did not consent may have influenced the results should they have participated. Likewise, because the study is cross-sectional, health status over time cannot be observed. Also, many of the data asked from the participants were self-reported (e.g. consultations with health professionals, medications taken, physical activities) and may be subject to recall bias. Some specific determinants of health and disease were not included in this study, including continuity of care, long-term care and the status of mental health care.

Despite these, the study also had its strengths. Regardless of many of the findings being self-reported, there were objective measures performed using validated tools (e.g., WHOQOL-BREF Filipino version, MNA, TUGT, FRT). The survey tool used by Project 1 was also validated through pre-testing and FGDs. Other objective measures were also used in describing health status like anthropometric measurements, laboratory testing, and medical and dental examinations performed by research-trained specialists. There was strength in the clinical assessments by at least one Geriatrician and adjudicated diagnosis by a senior Geriatrician, and one pair of licensed Dentists.

\section{Recommendations}

To support the call for the Philippine Plan of Action for Senior Citizens 2012-2016, ${ }^{31}$ which envisions "a society for all ages where the senior citizens are empowered to achieve active aging", the National Health Policy on Health and Wellness Program for Senior Citizens of the Department of Health has been created. ${ }^{32}$ The Order provides a national policy that shall guide the national and local actions towards the implementation of the Health and Wellness Program for Senior Citizens (HWPSC). The HWPSC focuses on the six program components; Policy, Standards, and Regulations, Health Financing, Service Delivery, Human Resources for Health, Health Information, and Governance for Health. Full implementation and support of this program are essential.

For the University of the Philippines Diliman, the following programs are recommended based on findings in this study: (1) Optimize access to health services thru 100 
percent Philhealth enrollment of retired employees, (2) medication assistance for the poorest retired personnel; (3) public health senior wellness and physical activity programs to reduce lifestyle-related NCDs; (4) an "Occupational Healthy Vision Program" from the time of employment thru retirement, to reduce the number of visual health problems reported; (5) sustained $\mathrm{flu}$ and pneumonia vaccination campaigns and finally; (6) a geriatrics orientation and training of University Health Service healthcare providers to help alleviate the lack of Geriatricians in the area.

The results of the study will be combined and analyzed with the same research from a semi-urban campus site, to understand and create a Framework for Active Aging that is relevant to this academic community.

\section{Acknowledgments}

1. Project Research Assistants and NIH Administrative Assistant.

2. Project Managers Dr. Myles Benigno and Dr. Grace Cruz

3. Statistician: Ms. Ma. Lourdes E. Amarillo, MPH (Biostatistics)

4. UP VPAA Dr. Ma. Cynthia Rose B. Bautista

5. Former UP VPAA Dr. Gisela P. Concepcion

6. EIDR AVP Dr. Carla Dimalanta

7. EIDR Staff Ms. Grace Reytas

8. UP Manila Chancellor Carmencita Padilla

9. UP Manila VC Arlene Samaniego

10. NIH UP Manila Executive Director Eva C De la Paz

11. NIH UP Manila Deputy ED Dr. Carmela Lapitan

12. UP Manila ERB

13. UP Manila Research Grants and Development Office

14. UP Manila Accounting

15. UP Diliman Chancellor Michael Tan

16. UP Diliman Health Service Director Dr. Jesusa Catabui

17. UP College of Social Sciences and Philosophy Chairman

18. UP CSSP Staff

International Collaborator:

Robert Cumming, MBBS NSW MPH PhD. The University of Sydney NSW Australia

\section{Statement of Authorship}

All authors participated in data collection and analysis, and approved the final version submitted.

\section{Author Disclosure}

All authors declared no conflicts of interest.

\section{Funding Source}

The study was funded by the Emerging Interdisciplinary Research Program of the Office of the Vice President for Academic Affairs, University of the Philippines.

\section{REFERENCES}

1. World Health Organization, Ageing and life-course, Publications on ageing and life-course: Active Aging: A Policy Framework [Internet]. 2002 [cited 2015 Jan]. Available from: http://whqlibdoc.who.int/ hq/2002/WHO_NMH_NPH_02.8.pdf?ua=1

2. De la Vega SF. Cultural validation of the WHOQOL-BREF in ambulatory community-dwelling Filipino older persons. Philippine Journal of Health Research and Development. 2013; 17:1-20.

3. Sugar JA, Pruitt K, Anstee JLK, Harris SG. Academic administrators and faculty retirement in a new era. Educ Gerontol. 2005; 31(5): 405-18. doi: 10.1080/03601270590921672

4. Cruz, GT, Natividad JN, Gonzales ML, Saito Y. Aging in the Philippines: Findings from the 2007 Philippine Study on Aging (PSOA) [Internet]. 2007 [cited 2017 Dec 22]. Available from: https://upd.edu.ph/aging-in-the-philippines/

5. Food and Nutrition Research Institute, National Nutrition Survey 2015 [Internet]. 2017 [cited 2017 Dec 22]. Available from: https:// fnri.dost.gov.ph/images/sources/AnnualReports/AR-2015.pdf

6. Philippine Statistics Authority, Census of Population 2010 [Internet]. 2012 May [cited 2015 Oct 20]. Available from: https://psa.gov.ph/ statistics/census/2010-census-of-population

7. National Institutes of Health Consensus Development Conference statement: geriatric assessment methods for clinical decision-making. J Am Geriatr Soc. 1988 Apr; 36(4):342-7. doi: 10.1111/j.15325415.1988.tb02362.x.

8. Katz S, Ford AB, Moskowitz RW, Jackson BA, Jaffe MW. Studies of illness in the aged The Index of ADL: A standardized measure of biological and psychosocial function. JAMA. 1963 Sep; 185(12):914-9. doi: 10.1001/jama.1963.03060120024016.

9. Lawton MP, Brody EM. Assessment of older people: Self-maintaining and instrumental activities of daily living. Gerontologist. 1969; 9(3):179-86.

10. Food and Nutrition Research Institute, Mini nutritional assessment (MNA) Filipino version. 2017 March 10.

11. Fried LP, Tangen CM, Walston J, Newman AB, Hirsch C, Gottdiener J, et al. Frailty in older adults: evidence for a phenotype. J Gerontol A Biol Sci Med Sci. 2001 Mar; 56(3):146-56. doi: 10.1093/ gerona/56.3.m146.

12. Woo J, Leung J, Morley JE. Comparison of frailty indicators based on clinical phenotype and the multiple deficit approach in predicting mortality and physical limitation. J Am Geriatr Soc. 2012 Aug; 60(8):1478-86. doi: 10.1111/j.1532-5415.2012.04074.x.

13. Fess EE. Grip strength. In: Casanova JS, editor. Clinical assessment recommendations, 2nd ed. Chicago: American Society of Hand Therapists; 1992. pp. 41-5.

14. Cruz G, Cruz CJ, Saito Y. Ageing and Health in The Philippines. Economic Research Institute for ASEAN and East Asia (ERIA); 2019.

15. Eibich P.Understanding the effect of retirement on health: Mechanisms and heterogeneity. J Health Econ. 2015 Sep;43:1-12. doi: 10.1016/ j.jhealeco.2015.05.001.

16. Müller T, Shaikh M. Your retirement and my health behavior: Evidence on retirement externalities from a fuzzy regression discontinuity design.J Health Econ. 2018 Jan; 57:45-59. doi: 10.1016/j.jhealeco.2017.10.005.

17. De Leon A. The Quality of Life of the Filipino Elderly in Selected Cities and Provinces [Internet]. 2014 [cited 2020 Mar 18]. Available from: https://tsaofoundation.org/

18. Department of Health, Office of the Secretary of Health. Circular 168-A. 1995.

19. Marfori JRA, Dans AML, Bastillo MOC, Paterno RPP, Rey MP, Catabui JT, et al. Equity in health benefit utilization and financial risk protection in outpatient and inpatient care: baseline survey of two socioeconomic groups of a pilot primary care benefits scheme in the catchment areas of a university-based health facility. Acta Med Philipp. 2019 Jan-Feb; 53(1):31-8. doi: 10.47895/amp.v53i1.1621

20. Kim C-B, Yoon S-J, Ko J. Economic activity and health conditions in adults aged 65 years and older: findings of the Korean National 
Longitudinal Study on Aging. Healthcare. 2017 Sep 26;5(4):63. doi: 10.3390/healthcare5040063.

21. Mallari RB. Successful Aging and Life Satisfaction of Older Filipinos: Evidence from the Philippine Longitudinal Study on Aging 2007. Philippines: University of the Philippines Diliman; 2011.

22. Badana ANS, Andel R. Aging in the Philippines. Gerontologist. 2018 Mar; 58(2):212-8. doi: 10.1093/geront/gnx203.

23. Noh J-W, Kim K-B, Lee JH, Kim MH, Kwon YD. Relationship of health, sociodemographic, and economic factors and life satisfaction in young-old and old-old elderly: a cross-sectional analysis of data from the Korean Longitudinal Study of Aging. J Phys Ther Sci. 2017 Sep; 29(9):1483-9. doi: 10.1589/jpts.29.1483.

24. Goodman J, Pappas JG. Applying the Schlossberg 4S Transition Model to Retired University Faculty: Does It Fit? Adultspan J. 2000 Mar; 2(1):15-28. doi: 10.1002/j.2161-0029.2000.tb00088.x

25. Department of Health. National Monitoring and Evaluation Dental Survey 2011.2011.

26. Dayrit M, Lagrada L, Picazo O, Pons M, Villaverde M. The Philippines Health System Review. Vol. 8. New Delhi: World Health Organization, Regional Office for South-East Asia; 2018.

27. Bulado E. The Status of Retired Faculty of Dumaguete City: Basis In Planning Retirement Development Program. Dumaguete City, Philippines: Siliman University; 1995.
28. Conner KA, Dorfman LT, Tompkins JB. Life satisfaction of retired professors: the contribution of work, health, income, and length of retirement. Educ Gerontol. 1985 Jan; 11(6):337-47. doi: 080/0380127850110602

29. Berba RP. In: dela Vega S. Maximizing the Quality of Life of the Elderly through Better Health. Manila, Philippines: National Academy of Science and Technology Philippines; 2006. pp. 21-29.

30. Norris T, Vahratian A, Cohen RA. Vaccination coverage among adults aged 65 and over: United States, 2015. NCHS Data Brief. 2017 Jun; (281):1-8.

31. Department of Social Welfare and Development, Issuances: Philippine Plan of Action for Senior Citizens 2012-2016 [Internet]. 2012 [cited 2015 Dec 20]. Available from: https://www.dswd.gov.ph/issuances/ AOs/AO_2015-005.pdf

32. Department of Health. Administrative Order No. 2015-009: National Health Policy on Health and Wellness Program for Senior Citizens [Internet]. 2015 [cited 2015 Dec 20]. Available from: https://www. doh.gov.ph/Health-and-Wellness-Program-for-Senior-Citizen

\section{The Acta Medica Philippina is now accepting limited advertising for its front and back cover (colored), as well as for available spaces in some of its pages, as appropriate. For inquiries and submission of proposals, please email us at actamedicaphilippina.upm@up.edu.ph}

